\title{
Exploration of Local University Teaching Management Reform under MOOC Background
}

\author{
Chen Li'e \\ Quanzhou Normal University \\ Introduction to the author: Chen Li'e, born in April 1974, female, born in Jinjiang, Fujian, the Han \\ nationality, bachelor degree, currently working in Quanzhou Normal University \\ hunter2011@foxmail.com
}

Keywords: MOOC; local university; teaching management

\begin{abstract}
With the development of scientific technology and the popularity of the Internet, educational informatization has become an important means for current teaching reform. The application of information technological means hastens MOOC, which provides strong platform for students' independent study and improves efficiency of local university educational management. Currently, MOOC teaching model has unparalleled advantages and it has been widely applied in overseas teaching circle. Its openness and transparency has won people's love. People can obtain relative teaching information through the Internet easily. MOOC online teaching model changes traditional teaching model and teaching methods, adding new content for educational concepts. It is necessary requirement to explore local university teaching management reform under MOOC background for current higher education globalization. Chinese universities should innovate and construct a whole set of local university teaching management system so as to fit MOOC teaching rapidly. This paper starts from the definition of MOOC, then it further analyzes and discusses challenges of MOOC teaching to traditional teaching management; lastly, it offers reforming suggestions to local university teaching reforms.
\end{abstract}

\section{Introduction}

With the development of the society, enterprises and employers have new requirements and standards to measure talents. As places to cultivate talents, universities are shouldered with the responsibility of transporting high-quality students, so they must conduct teaching reform. On the one hand, they should keep up with the direction of national teaching reform and innovate the current teaching methods and teaching content; on the other hand, with the popularity and development of information technology, universities can conduct teaching management with the help of Internet and information technology and improve teaching management efficiency. At present, Chinese universities are leading comprehensive reforms of teaching and education with innovative spirit and information-based teaching management is the essence of reform. Because of the rapid development of science and technology, the emergence of MOOC is forcing universities to conduct comprehensive reform, and there is high sense of urgency. When MOOC brings new and quality leaps for traditional teaching management, it also brings forceful challenges to traditional teaching management. Teaching management informatization is more embodied in deep, comprehensive and multi-link teaching management mode.

\section{Definition and characteristics of MOOC}

The full name of MOOC is massive open online courses, which is a large-scale, open and online course teaching form. It refers to large-scale Internet open courses normally. This kind of courses appears because of students who wish to enrich and improve themselves through Internet open courses.

MOOC has a lot of characteristics, and instrument resource diversification is the primary one. For example, MOOC can integrate multiple social networking instruments and integrate various 
digital resources and further constitute diversified learning methods and converge into abundant curriculum resources. Another characteristic is convenience, since MOOC is not restricted by time and space and people can enjoy excellent or distinctive courses in the world through Internet. MOOC has wide coverage; it is not restricted by population and its communication speed is fast. Another characteristic is that MOOC has strong participation autonomy. Compared with traditional courses, it has high flexibility and high enrollment rate. However, the dropout rate is also high. Therefore, it requires students to have strong autonomous learning ability and consciousness.

Since it has strong openness and low cost, MOOC is popularized rapidly in China recently. Since it is the combination of teaching and Internet, it is a burgeoning online teaching mode, it has brought huge challenges to teaching philosophy, learning method and teaching methods to Chinese universities. Under MOOC background, teaching management should also improve and complete university teaching management according to its own features and improve the teaching reform of MOOC.

\section{Challenges of MOOC teaching to traditional teaching management}

With the development of science and technology, Internet has huge influences on people's life, and MOOC is also rising in people's life with the steps of scientific development and rhythm of the Internet. In addition, the country has been implementing education reforms recently, and teaching and education informatization is an important goal for universities, so informatization reform of teaching management is an indispensable content in teaching reforms. Though the emergence of MOOC has brought great benefits to teaching and has improved learning efficiency, it has also brought serious threats to traditional teaching management. In recent years, domestic universities are all trying informatization reforms on teaching and education and informatization reform of teaching management is a critical link. Besides, with the rise of MOOC, this kind of reforms is playing a key role.

From the perspective of teaching operation, MOOC teaching transforms teaching of knowledge from inside the classroom to outside the classroom. Students can log in online courses to study and watch relative courses to finish the transmission of knowledge. Therefore, students can not only study in classroom, but also study in environment outside the classroom, for example, at home. Traditional teaching methods are mostly teaching in a large classes, while MOOC is dispersed learning, so students can study independently.

From the perspective of teaching mode, in traditional teaching, it mainly relies on theoretical teaching. In this mode, teachers are always subjects of teaching and they play the leading role, while students are merely passive learners. It mainly treats classrooms as site of teaching. While in MOOC, students are the subjects and they play the leading role in study. They are at the status of active learning, and the sites for teaching knowledge are not certain.

From the perspective of teaching interaction, in traditional teaching, students and teachers are face to face because of on-the-spot teaching; therefore, teachers and students can communicate and ask and answer. In addition, if teachers arrange discussions, students can discuss and communicate, which can strengthen emotional communication among students and cultivate students' teamwork spirit and cooperation awareness. However, in MOOC, since students can log in the platform and study, the learning sites are changed. There is no face-to-face communication between teachers and other classmates. Students cannot ask questions when meeting problems, and there will be no guide when they have confusions in study.

From the perspective of teaching quality evaluation, the popularity of MOOC will develop university teaching and class teaching system to dispersed online classrooms, which has increased difficulty of teaching evaluation. After all, evaluation subjects cannot understand the whole teaching process of MOOC. Therefore, compared with traditional classroom teaching evaluation, classroom evaluation of MOOC has met great challenges both in time and subject.

All in all, the popularity of MOOC not only brings challenges to traditional teaching viewpoints and learning methods, but also new threats to university teaching management system. Therefore, to 
maintain normal operation of university teaching, it needs to innovate the current teaching management and lay basis for completing MOOC teaching.

\section{Local university teaching management reform measures under MOOC background}

MOOC embodies a brand new teaching mode, and it forces comprehensive profound reforms in Chinese higher education. In order to guarantee ideal teaching quality for MOOC teaching form, the only necessary premise is to reform and innovate teaching management.

Establishing organization agency and constructing teaching platform. As universities, they need to establish relative organizational agencies to popularize MOOC so as to provide organizational guarantee. Organizational agencies of Chinese higher educational teaching courses must keep up with times and reform the traditional teaching agencies so that it can adapt to new teaching forms of MOOC and create necessary teaching environment, purchase relative teaching equipment and construct teaching platform for vast teachers and students. For example, local universities can establish "MOOC Teaching Center" of the local department, which is responsible for MOOC management, including updating, improvement of teaching resources and communication of teaching resources. In addition, it should construct MOOC teaching platform and lay basis for teaching reforms.

Making elaborate MOOC videos. MOOC courses mainly communicate knowledge through videos. Though MOOC courses have been popularized in a lot of universities, the videos are quite rigid and it is difficult to stimulate most of the students' initiative and enthusiasm. As local universities, they should start from students' perspective and make MOOC course videos carefully. For example, they can design online Q \& A and online discussion so that students can test their own learning progress and check whether they have grasped relative knowledge. The production of MOOC courses should be made according to the most cutting-edge knowledge of the major, and be sure not to copy the old textbooks and knowledge. As to past and foreign knowledge, universities should absorb the quintessence and get rid of the dross. For example, if local universities want to make courses of E-commerce, cases in the videos should not be restricted to Ma Yun, Liu Qiangdong and so on, they can also bring in some latest Internet finance, and they can even use the latest popular "Internet +" for teaching so as to guarantee the innovation and epochal character of the videos.

Strengthening MOOC course learning summary and assessment. Since students self-study the online MOOC courses, it is hard for teachers to supervise students' learning status compared with traditional class teaching. Therefore, it is difficult to grasp the real situation of students' learning effects. To guarantee the teaching quality of MOOC, MOOC course learning summary should be supervised. As local universities, they can operate like this: on the one hand, schools can ask students to write learning summary and finish relative assignments after the MOOC courses; teachers can even ask students to check each other or do teamwork to test students' learning effects. As to MOOC design, they can design automatic online assessment system in the videos. For example, class tests, class quiz and so on so that students can click in and study.

Teaching reform of MOOC courses are class videos mostly. Generally speaking ,the length of the videos are about 10 minutes and there would be some breaks which are for testing of students' learning effects (for example, a small quiz pops out for spot test and so on, and then the system will make automatic feedback), and then corresponding course teachers would check the teaching effects. Students click in and assess themselves automatically, and MOOC would pop out students' grades, which questions are answered wrongly and where the mistakes are, and there would be explanations.

Completing relative teaching management system. As local universities, corresponding system should be established and completed under MOOC background, especially teaching evaluation system. Because of the characteristics of MOOC courses, there are huge differences between its teaching evaluation and traditional teaching evaluation. As to teaching evaluation of MOOC courses, students' online evaluation can be adopted. That is to say, when students finish MOOC courses, they evaluate the Internet courses this time, including teaching content and quality 
of the video and so on. At the end of the semester, they can organize some student representatives to grade on this semester's MOOC courses. Some courses with low grades would be cancelled next week. In addition, to guarantee MOOC course quality, relative professional scholars and experts should be organized to evaluate this university's MOOC courses and some disadvantages should be improved. As local universities, reforms should be conducted from university course management, teaching operation management and teaching evaluation management and so on and relative system should be completed.

\section{Summary}

Generally speaking, MOOC has brought numerous conveniences to teaching of local universities, especially it has alleviated pressure of university teachers and stimulated students' initiative and interests; in the meantime, it has cultivated students' self-learning ability. However, MOOC has also brought severe challenges to local university teaching management. We should face university teaching management reforms with innovative spirit and treat it as a brand new system engineering to design according to new modes and new characteristics of MOOC teaching. Therefore, local universities should keep up with times and confront actively, establish organizational agencies and construct teaching platform, make MOOC videos carefully, strengthen MOOC course learning summary and assessment and complete relative teaching management system.

\section{Acknowledgements}

Fund program: teaching reform project of Quanzhou Normal University

Project number: (JAX14053)

\section{References}

[1] M.J. Guo, Z.Y. Ji. Reforms of MOOC to University Teaching Mode and Learning Ways_CComing of University Students' Self-education. Modern Education Science. 2014(11)

[2] Q.Z. Pan. Constructing Application-oriented University Course Teaching New Mode based on MOOC. Computer Light Disk Software and Application. 2014(21)

[3] H. Zhu, L. Zhao. Innovative Characteristics of MOOC and Informatization reform of University Teaching Way. Research of Chinese Higher Education.2014(12)

[4] X.W. Xu. Strengthening University Teaching Management Reform, Establishing Incentive Mechanism. Journal of Heilongjiang College of Education. 2000(03)

[5] X.Z. Liu, Z.M. Cao, R. Wang, G.Q. Qi. Exploration and Reform of Deepening College Teaching Management Reform. Chinese Forestry Education. 2003 (05) 